\title{
REVIEW ON COCONUT DEHUSKING AND CUTTING MACHINE
}

\author{
R. Navaneethan, N. Nikhil Prasath, G. Pradeep, K. \\ Santhana Prabhu \\ Department of Mechanical Engineering, Sri Eshwar \\ College of Engineering, Coimbatore, Tamilnadu, India.
}

\begin{abstract}
Coconut is one of the important ingredients in Indian household. It is widely used for cooking and also for the extraction of coconut oil. Though coconut is used widely in all parts of India, dehusking of coconut is not an easy task. Husk in botany is the outer shell or coating of a seed. It often may refer to the leafy outer covering of a coconut. Literally, a husk or hull includes the protective outer covering of a seed, fruit or vegetable. The dehusking machine is capable of removing husk from the coconut in an easy way and also time consumption is very less when compared to manual process. The model consists of a motor, gear arrangement, rollers with spikes, and a pressing plate.
\end{abstract}

Keywords- Husk, motor, rollers, Gears.

\section{INTRODUCTION}

In many rural areas, huge number of people involve in coconut dehusking process. Before extracting oil from the coconut, the coconuts undergo dehusking and cutting processes. So, to do this dehusking process people use sharp tools which consumes more time and also this is a risky process, because lack of concentration may lead to serious injury. Hence motorized dehusking and cutting machine can be used. This consist of set of rollers mounted by a spikes. These rollers are connected to a gears for power transmission purpose. This process is much faster than the manual process also easy to handle. The rollers are placed parallel to each other and is mounted with spikes. The spikes hence is used for the purpose of removing the outer most part of the coconut i.e the husk. The rollers are coupled with the shaft by using a bearing and gear arrangements. The rollers are then made to rotate in opposite directions which hence does the dehusking process. A motor with 1.5-2 HP and 1440rpm speed is suitable for performing this operation. Coconut dehusking and coconut cutting operations are carried out separately in individual units.

\section{LITERATURE SURVEY}

Anu S.C[1] et al in 2006 said that, coconuts are dehusked manually using tools. These methods required skilled labour. Attempts made so far in the development of dehusking tools have only been partially successful and not only been partially successful and not effective in replacing manual methods. The reasons stated for the failure of these tools include unsatisfactory and incomplete dehusking and breakage of the coconut shell while dehusking. Based on this hand operated coconut dehusking machine is being designed to solve this

\author{
A.R. Palanivelrajan (Assistant professor) \\ Department of Mechanical Engineering, Sri Eshwar \\ College of Engineering, Coimbatore, Tamilnadu, India.
}

problem. This machine takes into consideration the danger, hazards and risks involved in the dehusking the coconut which will be the efficient, productive, environmentally friendly, less laborious, easy to use and easy to assemble and disassemble, most importantly, cost effective in the production, maintenance and repair.

Luise cancel[2] et al in 2000said that,Coconut is a primary yield of konkan district and dehusking of coconut is essential process in preparing the coconut for additional usage. Coconut dehusking includes expelling of the husk from the coconut. Conventional dehusking is difficult and troublesome procedure. To beat these difficulties, to improve the robotization and to give security to the workers, another structure of dehusking machine is presented and created. This dehusker includes utilization of two flat rollers with arrangement of sharp apparatuses which would shear the husk from coconut when moving against one another. Shear force is required for dehusking of green coconut and dry darker coconut. Shear force required is more for green coconut than dry coconut. Torque and speed decrease required for dehusking is determined by utilizing the power required for shearing coconut. Ideal number of spikes is orchestrated on the rollers to dehusk the coconut with least power.

Chandra Dinath[3] et al said that, A machine explicitly intended to remove the husks from the coconut natural product including a majority of rollers pivoting in inverse ways adequately toward each other wherein every roller incorporates a majority of infiltrating spikes honed to enter and viably connect with the husk segment of the coconut organic product. The connection of the rollers in blend with the holding activity of the spike serves to tear away the husk from the nut leaving the nut in class.

Sujaykumar[4] et al said that Coconut dehusking includes expelling of the husk from the coconut. Conventional dehusking is tedious and troublesome procedure. To beat these restrictions, to improve the machining and to give security to the administrator, another structure of dehusking machine is presented and manufactured. This dehusker involves utilization of two even rollers with arrangement of sharp apparatus which would shear the husk from coconut when moving against one another. Shear power is required for dehusking of develop green coconut and dry dark colored coconut. Shear power required is more for develop green coconut than dry coconut. Torque and speed decrease required for dehusking is determined by utilizing the power required for shearing coconut. Ideal number of spikes is organized on the rollers to dehusk the coconut with least power. 


\section{International Journal of Engineering Applied Sciences and Technology, 2020 Vol. 4, Issue 10, ISSN No. 2455-2143, Pages 348-351 \\ Published Online February 2020 in IJEAST (http://www.ijeast.com)}

Shrinivas[5] et al in 2012 said that, The principle reason for this machine is to avoid people engaged with de-husking the coconut and to totally computerize the dehusking and crown evacuating process. Despite the fact that coconut dehusking machines have just been exhibited in the work and furthermore in some little scale ventures, the procedure is either manual or self-loader. A totally mechanized machine with manual stacking and emptying of coconuts will yield profitability higher than the current procedure. Thus, the present work is for the most part centered around a mechanized machine for dehusking and crown evacuating. Additionally, we can yield part of valuable and business items from coconut at different phases of its lifecycle. The machine focuses on de-husking and expelling the crown of the dehusked coconut of different sizes. So as to find a good pace the various sizes of the coconut, different spots are visited where overflowing yielding of coconuts are made. Likewise, dimensional information of coconuts have been gathered. In view of the overview the greatest and least sizes of the coconut are resolved. The machine is intended to suit various sizes of the coconut that are developed anyplace on the planet. Abi vargheser[6] et al said that, Dehusking of coconut is among the most-troublesome post-reap activities pertinent to coconut. Generally the whole husking is done physically utilizing either a cleaver or a crowbar, and it includes a lot of man power, expertise and preparing. There are bunches of machines developed everywhere throughout the world to automate this activity, however just a not many of them are accessible in showcase, tragically some of them have disappeared from the market and the rest have not come to the market yet because of numerous reasons. So an examination was directed about the different coconut husking machines which were made so far expressing what are focal points and burdens of them, the investigation included both the physically and automated renditions of husking instruments.

Rahul sabale[7] et al said that, There are many farm equipment's which are developed for the post harvesting operations. Mostly all the post harvesting operations are tedious jobs to perform. The dehusking of a coconut is regarded as the most time consuming,tiring, and difficult operation to perform. Many attempts has been done to perform this task of dehusking manually as well as mechanized. Traditionally this task of dehusking was performed by using different hand tools. By hand tools the dehusking depends on the skill of worker and involves training. The mechanized or the power operated machines are also developed to eliminate the drawbacks of manual tools. Such a tools and machines are developed all over the world and a very few have become popular, rest got vanished due to their limitations. This work is aimed to list such tools and machines which are used for the post harvesting i.e. dehusking of coconut

Sony Kuriakose [8] et al said that,Coconut husk is utilized in coir industry, shell as a fuel, copra as food, coconut water as nutritious fluid. The dehusking of a coconut is viewed as the most time consuming, tiring, and troublesome activity to perform and includes a lot of human efforts. Dehusking with customary hand devices like blade or a spike relies upon the ability of specialist and includes preparing. These days there is lack of such talented specialists. The automated or the force worked machines are created to dispense with the disadvantages of manual devices. This present work expects to plan and build up a self-loader coconut dehusking machine with taking out the previously mentioned downsides of the current instruments and machines. The machine imagined will have principle parts like dehusking unit mounted on a casing with electric motor as a power source alongside speed diminishing unit. The dehusking unit will have a couple of tube shaped rollers with tynes on its surface. These rollers will pivot in inverse bearing with various speeds so the tynes will infiltrate into the husk and tear it away from the shell. The best possible tearing of husk from shell happens when the coconut offers great work with the tynes and it relies upon the profundity of inclusion of nut into rollers and profile of tynes. Likewise the reasonable profile of tynes is required for powerful dehusking. These tynes will be joined to the chambers with clasp so substitution can be effortlessly done.

Vijay Kumar G Tile[9] et al said that,The fundamental goal of this machine is to evacuate the coconut shell and to dispense with the talented work associated with dehusking. The coconut external shell is a stringy husk one to two inches thick. This paper manages the structure and creation of pneumatic worked coconut dehusking machine. This venture is planned for delivering an proficient and progressively affordable machine for coconut industry. The coconut is referred to for its extraordinary adaptability as observed in numerous residential, business, and mechanical employments of its various parts. At the point when they develop they despite everything contain some water and can be utilized as seed nuts or prepared to give oil from the piece, charcoal from hard shell and coir from stringy husk. One conventional strategy utilized for coconut dehusking is utilizing a cleaver. This is finished by utilizing human vitality. This strategy is dangerous and monotonous but requires abilities. Consequently an option is recommended in our undertaking which lessens time engaged with coconut dehusking and human exertion. Contingent on the overview various sizes of coconut are resolved. The machine is intended to process various sizes of the coconut that are developed anywhere on the world. Sharanbasappa[10] et al said that, By and large coconuts are dehusked physically utilizing either a cleaver or a spike. These techniques require talented workers and are tiring to utilize. Attempts made so far in the improvement of dehusking instruments have been just mostly fruitful and not compelling in supplanting manual techniques. The reasons cited for the disappointment of these instruments incorporate unsuitable and deficient dehusking, breakage of the coconut shell while dehusking decay of valuable coir more noteworthy exertion required than manual techniques and so on.

Priyadharsini.S[11] et al said that,The Motorized type of remover for agriculture is a Mechanical gadget which is generally utilized in agricultural works. The Motorized coconut husk remover for agricultural needs reduces the time and labor in evacuating the husk. The purpose behind the improvement and the presentation of the Motorized coconut husk remover for agricultural is explained briefly. The Motorized coconut husk remover for agriculture is one of the improved device. 


\section{International Journal of Engineering Applied Sciences and Technology, 2020 \\ Vol. 4, Issue 10, ISSN No. 2455-2143, Pages 348-351 \\ Published Online February 2020 in IJEAST (http://www.ijeast.com)}

H. Radhwan[12] et al said that, A coconut de-husking machine contains two rollers with spikes, chain drives, presser, clearers, shafts and belting framework was created for little scale generation in provincial territories. Execution test investigation indicated that the machine de-husks coconut edible part with no nut breakage or on the other hand bending of the separated fiber length. The target of this venture is to improve the proficiency and profitability in delivering coconuts essentional part without husks by utilizing the best determination of mechanical devices with least expenses. One electric engine ( $2 \mathrm{hp}, 1500 \mathrm{rpm})$ is utilized to drive two shafts utilizing a blend of pulley and belt. In the middle of the engine and the poles, one box of worm gears is utilized to lessen the turn speed from 1500rpm to $21 \mathrm{rpm}$ (proportion 70:1). Two metal chambers with a progression of spikes are utilized to expel the husks from the coconut leafy foods appended to the revolving shaft. The machine's normal de-husking proficiency and limit are $90.42 \%$ and 222 coconuts for every hour, separately. Furthermore, the advancement of the machine is additionally an answer for the imperative of room, whereby a conservative size machine is increasingly appropriate for little and medium undertakings (SME's). In addition, it works with lesser clamor, which likewise adds to a progressively reasonable working condition for the condition.

K.P.Kolhe[13] et al said that, All the parts of coconut like coconut husk, shell, copra, coconut water are valuable. Coconut husk is utilized in coir industry, shell as a fuel, copra as nourishment, coconut water as nutritious fluid. There are many homestead gear's and apparatuses which are produced for the post reaping activity of green yields. The dehusking of a coconut is viewed as the most tedious, tiring, and troublesome activity to perform and includes a lot of human drudgery. Numerous endeavors has been done to perform coconut dehusking physically just as automated. Dehusking with customary hand devices like cleaver or a spike relies upon the expertise of specialist and includes preparing. These days there is lack of such gifted. Laborers. The motorized or the force worked machines are created to take out the disadvantages of manual apparatuses. Such manual devices and machines are built up everywhere throughout the world and a not many have become famous, rest got disappeared because of their constraints. The purposes behind the disappointment of these apparatuses incorporate inadmissible and inadequate dehusking, breakage of the coconut shell while dehusking, waste of valuable coir, more noteworthy exertion required than manual techniques, and so forth. This present work expects to structure and build up a self-loader coconut dehusking machine with taking out the previously mentioned disadvantages of the current apparatuses and machines. The machine considered will have primary parts like deshuking unit mounted on a casing with electric engine as a force source alongside speed decreasing unit. The dehusking unit will have a couple of tube shaped rollers with tines (cutting pins) on its surface. These rollers will pivot in inverse bearing with various speeds so the tines will enter into the husk and tear it away from the shell. The correct tearing of husk from shell happens when the coconut offers great work with the tynes and it relies upon the profundity of addition of nut into rollers and profile of tynes. As coconuts changes significantly fit as a fiddle there is a need of modification in separation between pair of rollers for wanted profundity of in area additionally the appropriate profile of tynes is required for compelling dehusking. These tynes will be joined to the chambers with latches so substitution can be handily done.

\section{CONCLUSION}

From this review the following conclusions are made,

- The coconut dehusking is one of the toughest and time consuming post harvesting operation.

- In India coconut is developed on an enormous scale. To process such an enormous number of generation of coconuts some appropriate system should be recognized or created.

- A few endeavors have been made to motorize the dehusking of coconut. Some of them were physically worked and others were power worked. These instruments have their own preferences and detriments.

- Some of them were problematic, tedious, power expending, uneconomical. There is a need to build up some instrument which would work acceptable and must be affordable.

\section{REFERENCE}

1) Anu, S.C, "Development and testing of a continuous power operated coconut husker", M. Tech project report submitted to the kelappaji college of agriculture engineering and technology (KCAET), Tavanur, 2012.

2) Luise Cancel, San Juan, Puerto Rico, "Coconut breaking machine".U.S Patent 3,605,834, Sept. 20, 1971.

3) Chandra Dinanath, Chaguanas, Trinidad and Tobago, "Coconut dehusking machine", US patent no 4,708,056, November, 24,1987.

4) G.Sujaykumar, Shashidhar B. Asantapur, Vishwas C., Prashanth Kumar, Dhanush D. "Design and Fabrication of Coconut Dehusker".Journal of Mechanical Engineering and Automation p-ISSN: 2163-2405 e-ISSN: 2163-2413 2017

5)Shrinivasan R, Zanwar and R.D.Kokate, "Advanced agriculture system" International Journal of Advanced Research in engineering \& Technology (IJARET), Volume 3, Issue 2, 2012,pp-111-118, ISSN Print: 0976-64180, ISSN Online: 0976-6499.

6) Vargheser, Jippu Jacob, "A Review of coconut husking machine", International Journal of Advanced Research in engineering \& Technology (IJARET), ISSN 0975-6995(Print) ISSN 0976 - 7002 (Online) Volume 5, Issue 3, September December (2014), pp. 68-78.

7) Rahul Sabale, K. P. Kolhe, "Review of Coconut Fiber Extraction Machines"International Journal of Science, Engineering and Technology Research (IJSETR), Volume 4, Issue 5, May 2015.

8) Amal PV, Sibin Sebastian, Abhiram Babu E, Albin Jose Saibu, Sony Kuriakose "Design and fabrication of cocout dehusking machine"'International Research Journal of Engineering and Technology (IRJET), e-ISSN: 2395-0056, pISSN: 2395-0072. 
9) Vijay Kumar G Tile, Praveen K, Prema D, Srikanth, Yashvanth B G, " Design and Fabrication of Pneumatic Operated Coconut Dehusking Machine" International Journal of Innovative Research in Science, Engineering and Technology, Vol. 6, Special Issue 15, December 2017.

10) Sharanbasappa, Narasimha Murthy C, Santosh S Kolli, "Design and Development of Hydraulic Coconut Dehusking Machine" International Journal for Research in Applied Science \& Engineering Technology (IJRASET) ISSN: 23219653; IC Value: 45.98; SJ Impact Factor: 6.887 Volume 5 Issue VII, July 2017.

11) Abishek.D, Aravind.S, Arun Koushik, Karthick.M and Priyadharsini.S, "Design and Fabrication of Automatic
Coconut Dehusking Machine", International Journal of Innovative and Emerging Research in Engineering Volume 4, Special Issue 1, NCIAR2k17.

12) H.Azmi, A. B. Sanuddin, M. Z. Zakimi, M. S. Jamali, H. Radhwan, A. N. M. Khalil, A. N. A. Akmal and A. F. Annuar, "Design and Development of a Coconut dehusking Machine (Machine Component Design)". Journal of Advanced Research Design ISSN (online): 2289-7984 | Vol. 4, No.1. Pages 9-19, 2015.

13) P.A.Wadile, K.P.Kolhe, "Design and Development of Coconut Dehusking Machine".International Journal of Advance Engineering and Research Development. Volume 4, Issue 5, May -2017. 